\title{
Emergency Response to Earthquake in Chile: Experience of a Cuban Field Hospital
}

\author{
Carlos R. Pérez MD MS
}

\begin{abstract}
This paper presents the author's experiences in deploying and later establishing a Cuban field hospital in response to the major earthquake that struck Chile in February 2010. It also reveals the initial difficulties the medical team faced and how collaboration with local social, medical and military partners contributed to response efficiency, and highlights the importance of Cuba's international health cooperation, especially in emergency situations. Over 254 days, Cuban health professionals had 50,048 patient encounters (outpatient visits and hospitalizations), a daily average of 197 . They performed 1778 surgeries (1427 major, $80.2 \%$ of total) and accumulated valuable experience in managing a field hospital in a disaster situation.
\end{abstract}

KEYWORDS Earthquake, humanitarian aid, health care, emergency response, disaster medicine, logistics, Chile, Cuba

\section{INTRODUCTION}

A devastating earthquake (8.8 on the Richter scale) struck Chile on February 27, 2010, its epicenter located some $325 \mathrm{~km}$ south of Santiago de Chile, the capital.[1] Cuban authorities immediately offered emergency humanitarian aid to the Chilean government. Acceptance was received on March 1, and at dawn the next day, a detachment of the Henry Reeve Emergency Medical Contingent[2] was deployed: 15 doctors (specialties included orthopedics, surgery, anesthesiology and family medicine), 12 nurses, 10 other health professionals (including a psychologist) and support staff, with a field hospital and 12 metric tons of medicines and supplies for hospital use.

After completing the necessary legal and organizational steps, the Cuban medical team was sent to Rancagua, the area selected by Chilean health authorities for the field hospital. Located about $90 \mathrm{~km}$ south of Santiago de Chile, Rancagua is the capital of Cachapoal Province and the 6th political-administrative region (Libertador Bernardo O'Higgins). It is an important commercial center in a territory with intensive agriculture and mining activity (including the Teniente mine, the largest underground copper mine in the world). Rancagua's urban population is approximately 250,000.[3]

The Cuban team arrived in Rancagua at about $0200 \mathrm{~h}$ on March 3. The search for an exact site to set up the hospital tents was conducted in close coordination with local officials. After evaluating the various options, the grounds of the Patricio Mekis sports complex were selected, two km from Rancagua's regional hospital and possessing excellent conditions for a field hospital. It had three soccer fields, an indoor gym, four tennis courts, a swimming pool, three warehouses, showers, restrooms and a cafeteria. Complex administrative facilities were close to the main soccer field.

The area was protected by a five-meter high perimeter fence; accessed through a large gate, facilitating passage of medical and support transport. An electrical connection could readily be hooked up to the perimeter lighting circuit. Water and sewage systems were located in the outer areas and the offices were suitable for a command post, equipped with telephone and Internet. Warehouses were adaptable to serve as kitchen, dining room and storage areas for medicines and hospital supplies.

The absence of tall buildings and the large expanse of the area made it likely that the complex would remain viable in the event of aftershocks. The soccer fields were well suited for quick and safe tent setup and there was sufficient room for all facilities needed for a field hospital.

\section{INTERVENTION}

Field hospital setup The work of erecting tents began immediately with the assistance of 12 Chilean soldiers. Setup and provisioning tasks were distributed among all team members, with help from 15 volunteers from 2 Chile-Cuba solidarity groups in Rancagua.

By $1600 \mathrm{~h}$ on March 3, the hospital's 10 tents had already been erected and installation of the internal electrical system (to provide power to all rooms) was under way. Five sets of clinical laboratory equipment, a portable X-ray machine, ultrasound, four cardiovascular monitors, ventilators and anesthesia equipment were installed. Work was under way to make the operating room functional, including installation of indispensable air conditioning units (Figure 1).

At $1700 \mathrm{~h}$ on March 3, general medicine and pediatrics services were up and running; that is, 19 hours after the team's arrival in Chile, thanks to joint Cuban and local efforts. This was especially important, since the earthquake had collapsed many of the struc-

Figure 1: Field hospital site

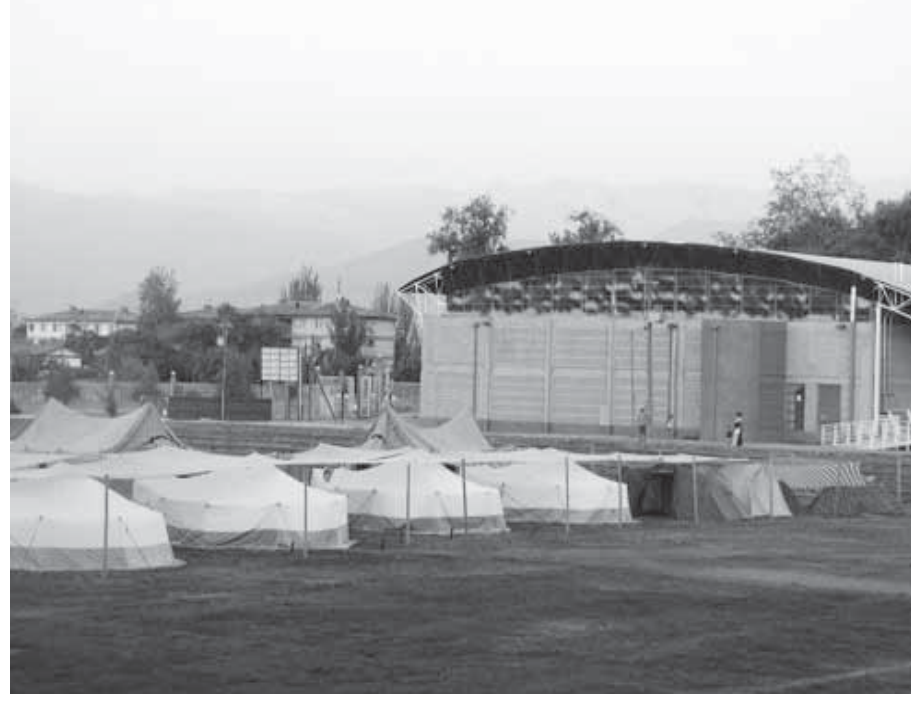


tures providing health care to the surrounding population, and left others with limited capacities. Emergency rooms in the region's three hospitals could only care for the injured and emergencies, whose numbers mounted as the days passed. Their surgical suites were running at $40 \%$ capacity, and operating and trauma rooms at $35 \%$, as reported by regional health authorities in the first emergency committee meetings attended by government officials.

Meanwhile, work continued late into the night. In the early morning hours of March 4, the team moved from the hotel, where its members had been staying since arrival in Rancagua, to newly created field quarters at the sports complex.

Medical and paramedical work shifts were organized, with 24 hours on followed by 24 hours off. Food services were established, with one hour each for lunch and dinner, and 20 minutes for break/snack time. Food was initially provided by the regional health service, with light meals prepared at the regional hospital. However, once the field hospital kitchendining room became operational in the complex's administrative area, at $2000 \mathrm{~h}$ on March 4, all the team's food was prepared there. Conditions for hospitalizing patients were already in place, in 2 10-bed wards and a 4-bed intensive care area. That afternoon, the operating room was also ready, including means for sterilization and preparation of surgical instruments.

At midnight, a summary of progress and planning for next day was done. A system was established for statistical reporting of cases seen, by specialty, for daily discussion during the morning handover meeting (where decisions were made on work organization, rest schedules and availability of most needed specialties). This statistical report would update local authorities on the health status of the population served by the field hospital and also update surgical waiting lists. By the end of March 4, the field hospital was fully operational (Figure 2).

Organization of medical care Guidelines were established for integrating the field hospital with the regional health system. It was agreed with regional health authorities that the hospital would treat all patients from any region who sought care, free of charge, including with first-line medications used in disaster situations, which were available. If necessary, the local Emergency Medical Care System would handle transfer of any patient requiring evacuation for more complex care than the field hospital could provide. Evacuation would be coordinated for some patients from Rancagua's regional hospital to the inpatient field hospital, to free up beds in the busiest services, mainly post-surgical and trauma recovery wards.[4]

Local health authorities requested that medical team leadership assign two general surgeons, two orthopedic surgeons, four anesthesiologists and four scrub nurses to cover positions in regional hospitals with facilities for more complex care but lacking qualified personnel. Four groups were created, each with an anesthesiologist and scrub nurse and either a general or orthopedic surgeon. This was designed to increase medical coverage and ensure important services to the population.[5]

The team agreed to provide the help requested, with prior approval of licenses and consultation with the region's Medical College, to avoid legal conflicts. A work schedule was established in the San Fernando and Santa Cruz hospitals, increasing the numbers of patients operated on daily. Effective integration into the regional health system created a positive work environment, in which humanitarian and fraternal cooperation prevailed among the two countries' health professionals.

Figure 2: Initial field hospital layout

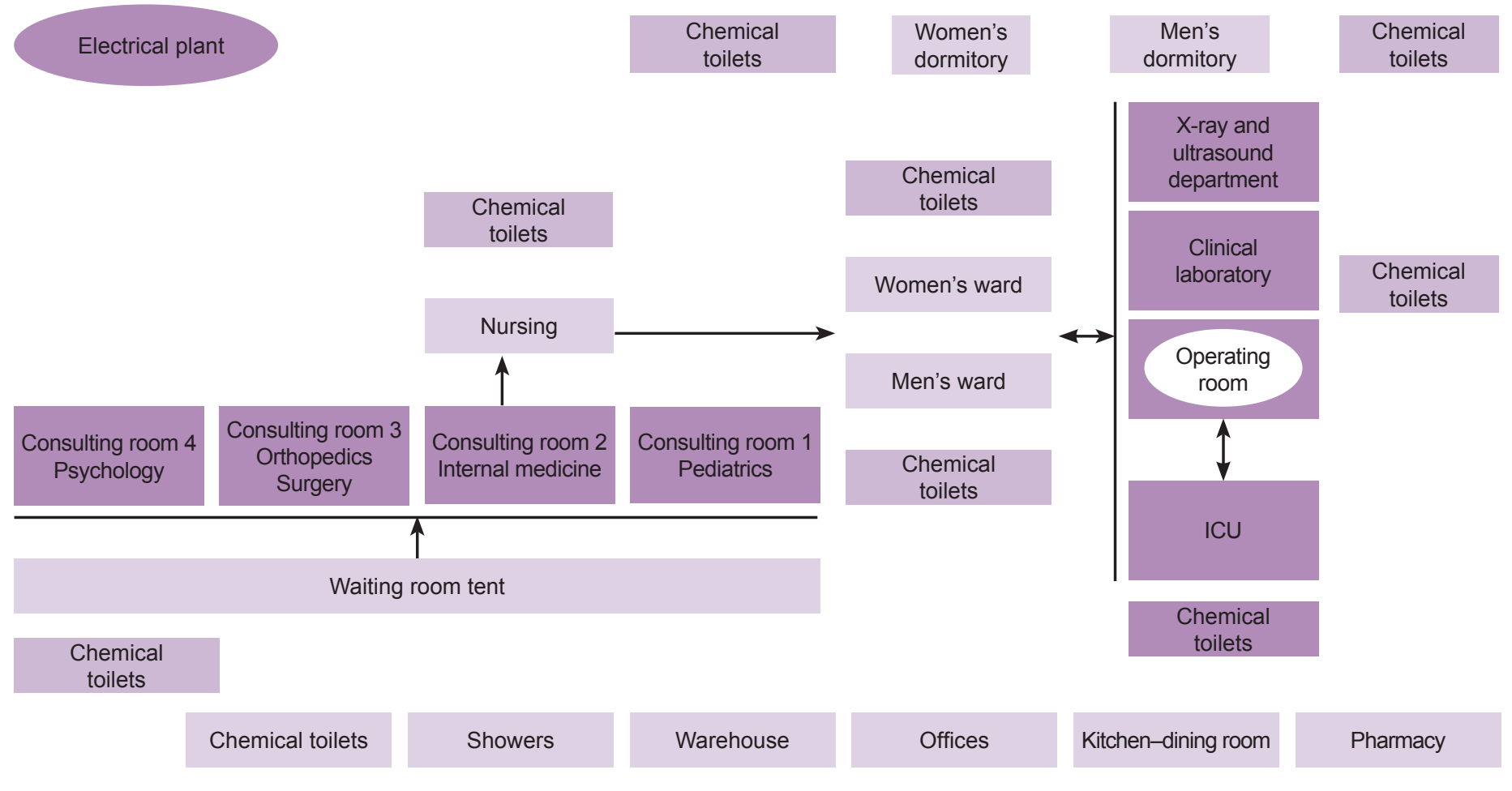


Regional health facilities contributed 24 specially outfitted beds to the field hospital, intended for patients recovering from general surgery and trauma (improving on the field hospital beds, which are simpler and lighter, but do not allow tilting for patient comfort and faster recovery). There were enough wheelchairs for internal transfer, and some additional gurneys were added. Food for hospitalized patients was provided by the regional hospital, with transportation coordinated through the regional health authority. Individual medical diets prescribed for each patient were strictly observed.

Installation of a generator ensured $\geq 12$ hours of self-sufficiency in case of blackouts, providing greater security for monitoring critically ill patients and performing surgery.

Organization of local personnel support On the third day of operations, seven young Chilean graduates of Cuba's Latin American Medical School (ELAM ) arrived at the complex, having heard in the local media that a Cuban hospital was in the region. They joined the team as volunteers, donating their weekend free time to take shifts at the hospital. Later, five more young Chilean doctors joined the field hospital work, ELAM graduates who had just returned from Haiti, where they volunteered with Cuban health professionals in the Henry Reeve Emergency Medical Contingent responding to the earthquake there.[2] Support was also received from four Chilean doctors who had studied in Cuba in the 1970s and were well-established physicians in Chile.

Our efforts had the support of the Chilean armed forces, commanded by General Antonio Yakcich, head of a special air force unit in the 6th Region; an entire company of the engineering corps assisted in rapid installation of the field hospital.

Setting up a field hospital is not an overly complex process, but is laborious due to the amount of heavy equipment to install. Chilean soldiers took on the toughest tasks, relieving Cuban doctors of these functions, thus preventing possible accidents and injuries to them during setup.

Hospital preparation for rainy season and winter After the hospital had been operational for three months, health authorities asked for extension of Cuban emergency services to continue supporting local health institutions. Accordingly, they proposed improvements to team living conditions for the impending rainy season and winter.

It was decided to move the hospital facilities to the gym beside the soccer fields. The building was structurally sound and, most important, had withstood the ravages of the February 27 earthquake and March 11 aftershock without major damage. Use of the new facilities involved adapting ground-floor sections for consulting rooms, as well as clinical laboratory, pharmacy and radiology departments; some rooms used as wards; adjacent to these, a four-bed intensive care unit; and the operating room located conveniently close to the postsurgical recovery area.

Local health service hygiene and epidemiology experts were asked for a biosafety assessment to avoid contamination risks and complications from nosocomial infections.[6] Tent bedrooms for medical and paramedical personnel were proposed on the gym's second level, formerly a basketball court, thus effectively isolat- ing staff rest areas from the rest of the complex. After assessing all the expected weather variables it was decided to transfer the entire hospital facility to the gym. To minimize patient-care impact, the transfer was made on a weekend, within 48 hours completely relocating the hospital, which was ready to continue providing services.

\section{RESULTS}

The Cuban medical team in Chile worked for 254 days in the Rancagua field hospital; there were 50,048 patient encounters (outpatient visits and hospitalizations), a daily average of 197; 1778 surgeries were performed, 1427 (80.2\%) of them major. The predominant major surgeries were related to gallbladder and biliary tract conditions (570 patients or $39.9 \%$ of major surgeries), achieving a significant decrease in the waiting lists for elective cholecystectomy.

Problems with the musculoskeletal system (caused by direct or indirect trauma during the earthquake) were the most frequent cases seen during the first three months, accounting for 5850 patient encounters, $33 \%$ of the 17,730 during the trimester. Next came cardiovascular diseases due to uncontrolled hypertension, accounting for 4964 patient encounters (28\% of total). Psychological problems were in third position, with symptoms such as anxiety, fear, panic attacks, insomnia, nightmares, phobias and sadness; they motivated 3900 patient encounters (22\%).

During the last trimester of the Cuban medical team's work, the most frequent problems treated were respiratory infections caused by rhinovirus and respiratory syncytial virus, especially in children, with 9574 patient encounters $(59.2 \%$ of 16,159 in this trimester).

\section{LESSONS LEARNED}

\section{General}

- Effective response capacity was demonstrated by Cuba's Central Medical Cooperation Unit: in 12 hours an experienced, expert medical team was mobilized, equipped with a full field hospital and all essential medicines and hospital supplies for disaster response.

- The team contributed substantially to health care indicators in handling patient demand for elective surgery and treatment of chronic non-communicable diseases, as well as psychological and emotional problems secondary to the earthquake's impact (quite common in the population served).

- Cuban cooperants' medical activity was useful not only in providing immediate response to the natural disaster in Chile, but also during the recovery period.

\section{Logistics and infrastructure}

- The experience highlighted the importance of a detailed review of the logistical resources of each field hospital before transfer to disaster areas; for example, not all countries affected by disaster can ensure availability of adjustable beds for surgical recovery and intensive care.

- A proper assessment of any proposed field hospital site should be made to ensure maximum efficiency and harmonious interaction with the local health network.

- The importance was underscored of establishing an adequate system for collecting and processing statistical data useful to health officials of both countries to facilitate joint decision-making. 
- Military support (with its organization, professionalism and discipline) was essential to set up the field hospital swiftly.

\section{Operating Principles}

- Strictly respecting the local legal framework and established protocols, the Cuban medical team's integration with Chilean civil and military authorities, the regional health network, local solidarity groups and Chilean ELAM graduates strengthened the mission and facilitated successful health interventions.

\section{RECOMMENDATION}

It is essential to include the psychologists in the composition of medical teams working in disaster situations, to provide a comprehensive response to health care demand. -1 -

\section{REFERENCES}

1. López Tagle E, Santana Nazarit P. El terremoto de 2010 en Chile: respuesta del sistema de salud y de la cooperación internacional. Rev Panam Salud Pública. 2011;30(2):160-6. Spanish.

2. Gorry C. Haiti One Year Later: Cuba's Medical Team Draws on Experience and Partnerships. MEDICC Rev. 2011 Jan;13(1):52-5.

3. Ministry of Planning (CL). CASEN 2009: Encuesta de Caracterización Socioeconómica Nacional. Santiago de Chile: Ministry of Planning (CL); 2010. Spanish.

4. Barría S. Rol de la atención primaria en la respuesta del sistema de salud chileno frente al terremoto-maremoto de Febrero 2010. Santiago de Chile: World Health Organization; Pan American Health Organization; 2010. Spanish.
5. Ministry of Health (CL). Subsecretaría de Redes Asistenciales. Informe Coordinación Nacional de Reconstrucción Hospitalaria. Santiago de Chile: Ministry of Health (CL); 2010 Jun. Spanish.

6. Ministry of Health (CL); Pan American Health Organization, World Health Organization. Plan de Acción en Salud Ambiental. Santiago de Chile: Ministry of Health (CL); 2010 Mar 26. Spanish.

\section{THE AUTHOR}

Carlos R. Pérez Díaz (bnum@infomed.sld.cu), internist with a master's degree in emergency medicine. Member of Cuba's Henry Reeve Emergency Medical Contingent and director of the Rancagua field hospital in 2010. Director, National Medical Emergency Center, Ministry of Public Health, Havana, Cuba.

Submitted: October 28, 2014

Approved for publication: June 28, 2015 Disclosures: None 